\title{
Erratum: Feature-based performance of SVM and KNN classifiers for diagnosis of rolling element bearing faults
}

\author{
Mohd Atif Jamil', Md Asif Ali Khan², Sidra Khanam ${ }^{3}$ \\ Department of Mechanical Engineering, Aligarh Muslim University, Aligarh, India \\ ${ }^{1}$ Corresponding author \\ E-mail: ${ }^{1}$ atif.mechtech@gmail.com, ${ }^{2}$ asifalikha28@gmail.com, ${ }^{3}$ sidrakhanam@zhcet.ac.in
}

DOI https://doi.org/10.21595/vp.2021.22353

Check for updates

Copyright $\odot 2021$ Mohd Atif Jamil, et al. This is an open access article distributed under the Creative Commons Attribution License, which permits unrestricted use, distribution, and reproduction in any medium, provided the original work is properly cited.

\section{Publisher's note regarding paper}

Mohd Atif Jamil, Md Asif Ali Khan, Sidra Khanam Feature-based performance of SVM and KNN classifiers for diagnosis of rolling element bearing faults. Vibroengineering Procedia, Vol. 39, 2021, p. 36-42, https://doi.org/10.21595/vp.2021.22307.

\section{The description of the correction}

Fig. 2 demonstrated KNN algorithm incorrectly in the original article approved (after the acceptance) by the authors.

The incorrect figure:

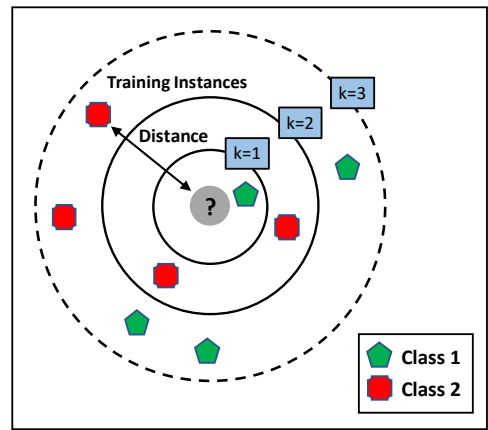

Fig. 2. A demonstration of KNN algorithm

The revised figure is as follows:

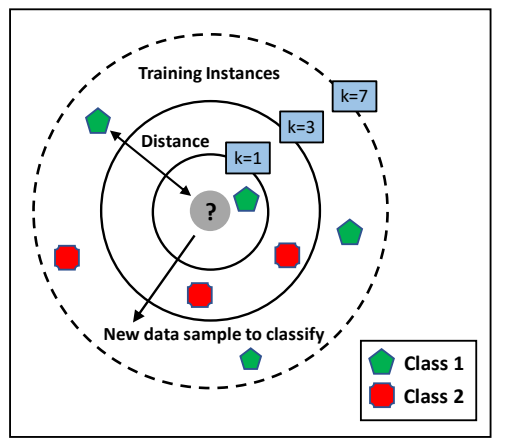

Fig. 2. A demonstration of KNN algorithm 